Article

\title{
Impact-Rubbings Dynamics Behavior of Magnetic-Liquid Double Suspension Bearing in Electromagnetic Failure Model
}

\author{
Jianhua Zhao ${ }^{1,2}$, Lanchun Xing ${ }^{1}$, Xuchao Ma ${ }^{1} \mathbb{D}$, Yongqiang Wang ${ }^{1}$, Dianrong Gao ${ }^{1}$ and Guojun Du ${ }^{2, *}$ \\ 1 Fluid Power Transmission and Control Laboratory, Yanshan University, Qinhuangdao 066004, China; \\ zhaojianhua@ysu.edu.cn (J.Z.); xinglanchun@foxmail.com (L.X.); mxc18630334372@163.com (X.M.); \\ wang1245128709@163.com (Y.W.); gaodr@ysu.edu.cn (D.G.) \\ 2 College of Civil Engineering and Mechanics, Yanshan University, Qinhuangdao 066004, China \\ * Correspondence: dugj2002@ysu.edu.cn
}

Featured Application: This work was supported by the National Nature Science Foundation of China (No. 52075468); General project of Natural Science Foundation of Hebei Province (E2020203052); Youth Fund Project of scientific research project of Hebei University (QN202013); Open Project Funding of Fluid Power Transmission Control Laboratory of Yanshan University.

Citation: Zhao, J.; Xing, L.; Ma, X.;

Wang, Y.; Gao, D.; Du, G

Impact-Rubbings Dynamics Behavior of Magnetic-Liquid Double Suspension Bearing in Electromagnetic Failure Model. Appl. Sci. 2021, 11, 6345. https://doi.org/ 10.3390/app11146345

Academic Editor: Ilaria Cacciotti

Received: 30 May 2021

Accepted: 5 July 2021

Published: 8 July 2021

Publisher's Note: MDPI stays neutral with regard to jurisdictional claims in published maps and institutional affiliations.

Copyright: (c) 2021 by the authors. Licensee MDPI, Basel, Switzerland. This article is an open access article distributed under the terms and conditions of the Creative Commons Attribution (CC BY) license (https:// creativecommons.org/licenses/by/ $4.0 /)$

\begin{abstract}
Magnetic-liquid double suspension bearing (MLDSB) is a new type of suspension bearing with electromagnetic suspension as the main part and hydrostatic supporting as the auxiliary part. It can greatly improve the bearing capacity and stiffness of rotor bearing system and is suitable for medium speed, heavy load, and frequent starting occasions. The electromagnetic system adopts PD control, and hydrostatic system adopts constant pressure supply model to adjust and control the rotor's displacement in real time. Once bearing electromagnetic system fails, the "dropping-collision" phenomenon of the rotor will be triggered in operation process, leading to cracking and shedding of magnetic sleeve plating and magnetic pole plating. Then the operational reliability and stability of MLDSB will be greatly reduced. So in this paper, Firstly, the drop impact-rubbing equation of the single DOF bearing system under four failure models (upper unit failure, lower unit failure, bilateral failure, and power amplifier failure) is established. Secondly, the paper simulates influence laws of different structure and operation parameters (plating/liquid film thickness and oil pocket pressure, bias current) on falling rotor impact-rubbings behavior. The results show that: (1) the degree of "dropping-collision" of the rotor under the four failure models is successively as follows: power amplifier failure $>$ upper unit failure $>$ bilateral failure $>$ lower unit failure. (2) Due to the impact-rubbing damping effect of hydraulic oil, it plays a certain inhibitory and buffering role on the phenomenon of "drop-collision". The degree and probability of "dropping-collision" of rotor can be effectively reduced by increasing the pressure of oil chamber appropriately. (3) The rotor drop impact-rubbing behavior obtained from the test is basically consistent with the theoretical simulation, and the correctness of the theoretical simulation can be effectively verified. The research provides a theoretical basis for fault prevention and diagnosis of MLDSB.
\end{abstract}

Keywords: magnetic-liquid double suspension bearing; single DOF supporting system; dropping impact-rubbings; electromagnetic failure model; structural parameters; operation parameters

\section{Introduction}

MLDSB is a new type of suspension bearing which is mainly composed of electromagnetic suspension and auxiliary by hydrostatic force bearing. The bearing capacity is greatly enhanced, and the operation stability and service life can be effectively improved. It is suitable for hydroelectric power, deep-sea exploration, and other fields, especially the medium speed overloading, frequently starting.

The structure of MLDSB test stand is composed of motor, coupling, radial bearing, axial bearing, axial motor, radial motor, step shaft, bracket as shown in Figure 1. 


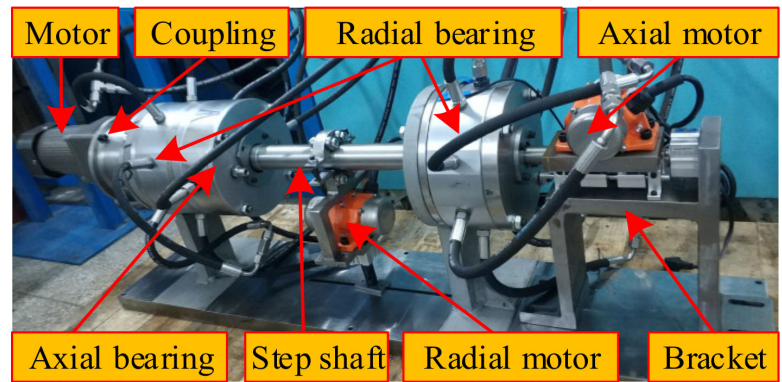

Figure 1. Structure of MLDSB.

The radial unit of MLDSB is composed of rotor, magnetic sleeve, supporting chamber, magnetic pole, oil inlet/return hole, shell, coils as shown in Figure 2. The poles and the magnetic sleeve are chrome-plated in order to protecting from corrosion by long-term immersion in oil. [1-3].

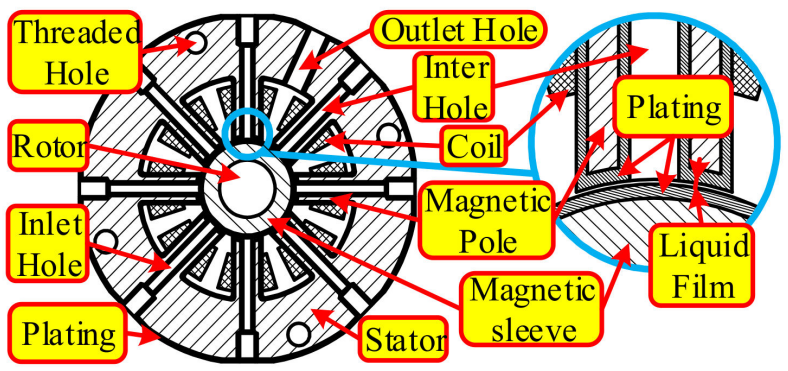

Figure 2. Sectional view of magneto-liquid double suspension radial unit.

The regulation principle of MLDSB as shown in Figure 3. PD control and constant pressure supply model are separately adopted in the electromagnetic system and hydrostatic system to realize real time regulation of the rotor [4].

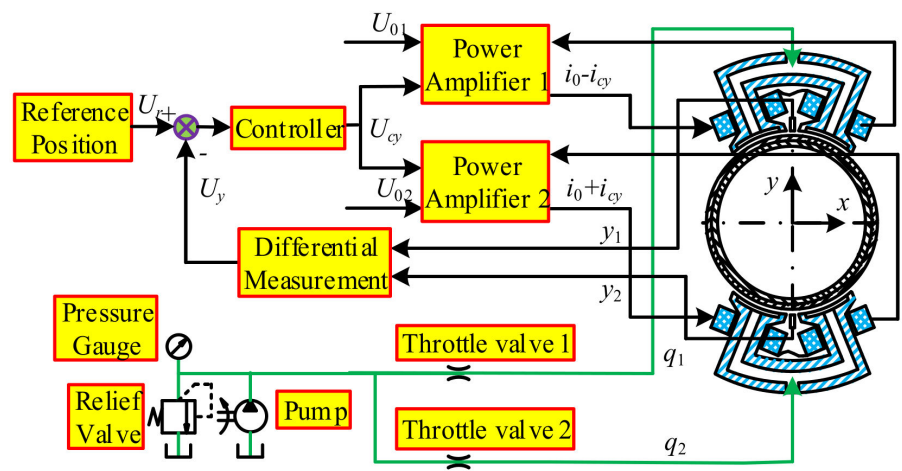

Figure 3. Single DOF control system of MLDSB.

In the actual operation process, electromagnetic system failure [5,6] will be caused by electromagnetic coil corrosion and power amplifier circuit fault, which will lead to the phenomenon of "dropping-collision" between rotor and stator. The excessive wear, cracking, and shedding of magnetic sleeve and stator plating can be triggered, and the operational stability and reliability will be reduced.

In recent years, many scholars at home and abroad had studied the dropping phenomenon of rotor/bearing on system, and had achieved fruitful results.

Professor JARROUX [7] investigated numerically and experimentally the rotor drop impact-rubbings when unexpected Active Magnetic Bearings (AMBs) shut down occurs. 
Rotor drop simulations in the time domain were carried out by using the Finite Unit method and the three TDB models. Predicted and measured rotor drop responses were compared regarding the displacements as well as transmitted loads and permits evaluating the model efficiency.

Professor PATPICK [8] considered viable control methods that the magnetic bearing was still functional when contact arise from intermittent faults or overload conditions. The results demonstrated that appropriately phased synchronous forcing could destabilize synchronous forward rub responses. Alternatively, small whirl motions of a touchdown bearing could also be beneficial without disturbing the main magnetic bearing control loop.

Professor PESCH [9] proposed a novel robust control strategy that is proposed for ensuring levitation recovery. The strategy utilized model based-synthesis to find the requisite $\mathrm{AMB}$ control law with unique provisions to account for the contact forces and to prevent control effort saturation at the large deflections that occur during levitation failure.

Professor Zhao [10] established a detailed impact-rubbing model to reveal the behavior of the dropping rotor. Additionally, a PID control system for a magnetic bearing was designed with combination of contact possibilities. The control strategy mentioned in this paper was demonstrated theoretically as being effective in returning a rotor to the contactfree levitation position and avoiding further fierce contacts under several circumstances when external disturbance involved.

Professor Wang established a mechanical model for rotor drop and crash has been developed. A simulated rotor system was modeled by the finite unit method. The results showed that when the dropping at high speeds, if the kinematic energy of the rotor was not properly reduced, the rotor will whirl inside the backup bearings for a long time, introducing remarkable contact stress and deformation.

Professor Xu [11-14] studied the situation of self-eliminating clearance protection bearing after the failure of active electromagnetic bearing. Compared with the traditional roller bearing, a self-eliminating clearance protection bearing can significantly reduce the vibration of rotor falling behind and make the dropping of high-frequency speed more reliable.

Professor Jin [15] studied the rotor orbits and the contact forces between rotor and inner race are simulated respectively after rotor drop on DDCBs (Double layer trap bearing) and SDCBs (Single layer trap bearing). The result shows that the rotor vibration range using DDCBs is significantly smaller than that using SDCBs. The maximum contact forces drop about $15 \% \sim 27 \%$ compared with the contact forces using SDCBs. It is concluded that DDCB is helpful to reduce vibration amplitude and impact force.

Professor Jin [16] studied the contribution of parameters such as unbalance; air gap, coefficient of friction, and coefficient of restitution to drop dynamics of the rotor are examined. When the unbalance is small, the resulting motion is also small. As the level of unbalance increases, the motion of the rotor becomes larger, so there is potential for damage to the rotor and the backup bearings.

Professor Zhu [17] studied the transient nonlinear dynamic characteristics of a multidisc rotor system when the rotor dropped on the standby bearing after the failure of the active electromagnetic bearing. The results show that the using of the bearing with large damping flexible structure can significantly improve the transient dynamic characteristics of the rotor dropping on the standby bearing, and reduce the impact of the rotor dropping on the life and reliability of the standby bearing.

Professor Jiang [18] used ADAMS to model a new type of protective bearing, namely double-layer rolling bearing, and simulated the movement process of rotor drop in the bearing. The simulation results of rotor dropping trajectory and contact force show that double-layer rolling bearing can reduce the impact caused by rotor dropping.

To sum up, the traditional rotor drop-impact-rubbings study mainly focus on impactrubbing characteristics and law of drop-in active electromagnetic bearing system under fault. Due to the coupling of the electromagnetic and hydrostatic system, the rotor "fallingrubbing" fault in the electromagnetic failure model is more complex. In addition, the 
traditional protective bearing is replaced by hydrostatic system, so that the "falling-rubbing" load can act directly on the plating of magnetic sleeve and pole. The excessive wear and fatigue cracking of magnetic sleeve and pole can be triggered, which seriously affects the operation stability and reliability of the MLDSB.

Therefore, single DOF dropping model of MLDSB is established in this paper to numerically simulate the influence of structure parameters (plating thickness and liquid film thickness), operation parameters (oil pocket pressure and bias current) on displacement of rotor, collision force, and supporting characteristics.

\section{Drop Impact-Rubbings Model of Single DOF Supporting System}

Since the Drop Failure occurs for a very short time, the following assumptions are presented $[19,20]$ :

(1) There is the local elastic collision and elastic deformation between the magnetic pole and the magnetic sleeve.

(2) The winding magnetic flux leakage, edge magnetic flux, eddy current loss, core material saturation, and coupling effect between magnetic poles are ignored.

(3) The small gap between the supporting cavities is ignored.

(4) The liquid inertia force and viscous pressure characteristics is ignored.

\subsection{Mathematical Model of Single DOF Supporting System}

Combined with the literature [4], a single DOF mechanical model of supporting system is established in y direction.

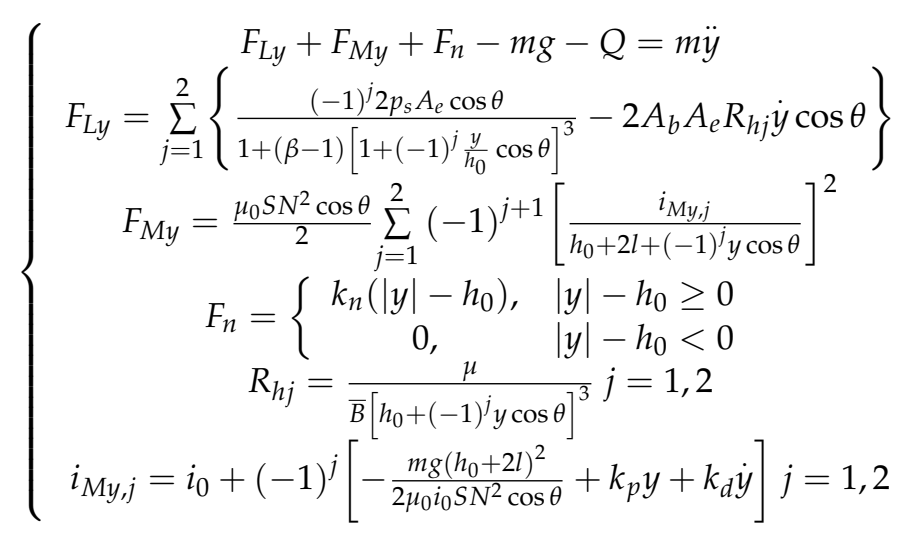

where, $F_{L y}$ is hydrostatic force in y direction [21]; $p_{s}$ is oil supply pressure; $A_{e}$ is bearing area of supporting pocket. $A_{b}$ is extrusion area of supporting pocket; $R_{h j}$ is liquid resistance of oil pocket; $\mu$ is oil viscosity; $h_{0}$ is liquid film thickness; $\bar{B}$ is flow coefficient [22]; $\theta$ is Angle between supporting pocket and centerline of rotating shaft. $B$ is throttling ratio; $F_{M y}$ is electromagnetic force in y direction [23]; $i_{M y, j}$ is input current; $i_{0}$ is bias current; $\mu_{0}$ is vacuum permeability; $S$ is area of magnetic pole; $N$ is turn of electromagnetic coil; $l$ is plating thickness; $k_{p}$ and $k_{d}$ are proportion and differential coefficients. $F_{n}$ is radial impact force [24]; $k_{n}$ is radial stiffness; $G$ is rotor weight.

\subsection{Single DOF Drop Model in Electromagnetic Failure Model}

Electromagnetic failure can be divided into four models: upper unit failure, lower unit failure, bilateral failure, and power amplifier failure. The rotor drop impact-rubbings model under various failure models is shown as follows:

(1) Upper unit failure: Let $F_{M y, 1}=0$ in Equation (1).

(2) Lower unit failure: Let $F_{M y, 2}=0$ in Equation (1).

(3) Bilateral failure: Let $F_{M y, 1}=F_{M y, 2}=0$ in Equation (1).

(4) Power amplifier failure: Let $i_{M y, 1}=i_{M y, 2}=i_{0}$ in Equation (1). 


\section{Numerical Simulation of Drop Process of Single DOF System}

The initial design parameters of MLDSB are shown as Table 1.

Table 1. Initial design parameters of MLDSB.

\begin{tabular}{ccc}
\hline Symbol & Variable & Size \\
\hline$i_{0}$ & Biasing circuit & $1 \mathrm{~A}$ \\
$p_{s}$ & Supply pressure & $0.1 \mathrm{MPa}$ \\
$\beta$ & Throttling ratio & 2 \\
$\mu$ & Dynamic viscosity & $1.3 \times 10^{-3} \mathrm{~Pa} \cdot \mathrm{s}$ \\
$m$ & Mass of rotor & $4 \mathrm{~kg}$ \\
$\mu_{0}$ & Permeability of air & $4 \pi \times 10^{-7} \mathrm{H} / \mathrm{m}$ \\
$A_{e}$ & Area of supporting cavity & $416 \mathrm{~mm}^{2}$ \\
$A_{b}$ & Extrusion area & $56 \mathrm{~mm}^{2}$ \\
$h_{0}$ & Oil film thickness & $50 \mu \mathrm{m}$ \\
$\theta$ & Angle & $22.5^{\circ}$ \\
$B$ & Flow coefficient & 0.71 \\
$S$ & Area of pole & $1080 \mathrm{~mm}^{2}$ \\
$N$ & Turns per coil & 50 \\
$Q$ & Load & 100 \\
$k_{n}$ & Stator stiffness & $3.5 \times 10^{8}$ \\
$l$ & Plating thickness & 100 \\
\hline
\end{tabular}

Simulation range of structure and operation parameters: $h_{0}=(30 \sim 80) \mu \mathrm{m}, l=(50 \sim 100) \mu \mathrm{m}$, $i_{0}=(1 \sim 2) \mathrm{A}, p_{s}=(0.1 \sim 1.0) \mathrm{MPa}$.

\subsection{Drop Impact-Rubbings Behavior of Upper Unit Failure Model}

3.1.1. Influence of Structural Parameters on Rotor Impact-Rubbing Behavior

In the upper unit failure model, the maximum radial impact force of the rotor/stator collision varies with the structural parameters as shown in Figure 4.

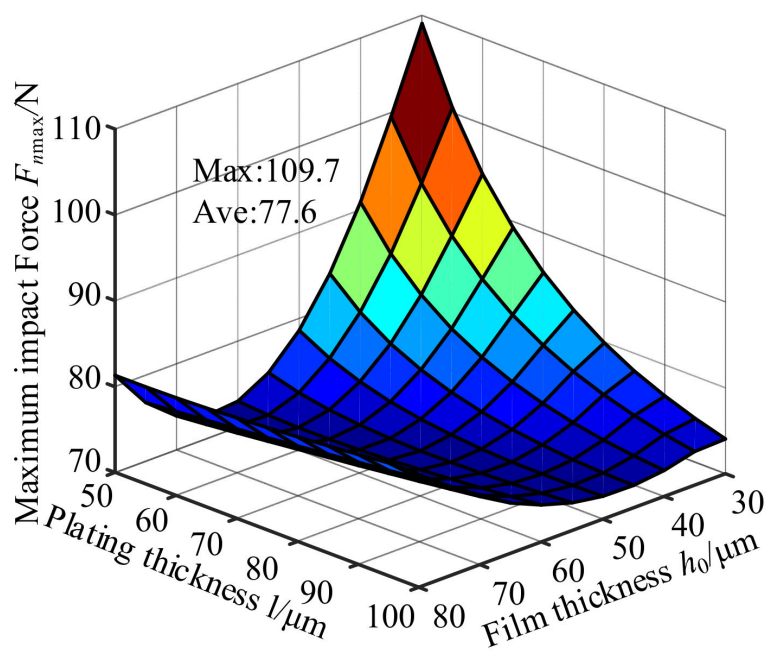

Figure 4. Maximum radial impact force upper unit failure model.

According to Figure 4, the maximum radial impact force decreased firstly and then increased with the increase of liquid film thickness, and decreased with the increase of plating thickness. The maximum value occurs in the combination of $h_{0}$ is $30 \mu \mathrm{m}$ and $l$ is $50 \mu \mathrm{m}$. Therefore, take it as the typical example in order to analyze the operation rules as shown in Figure 5. 


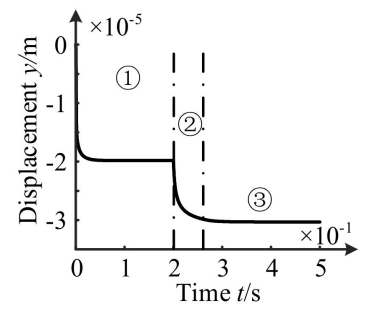

(a) Displacement

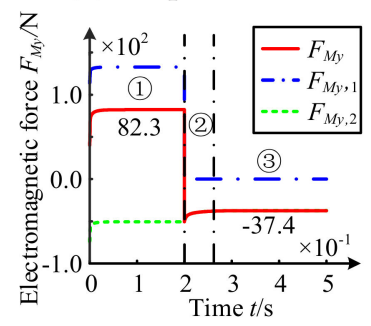

(c) Electromagnetic Force

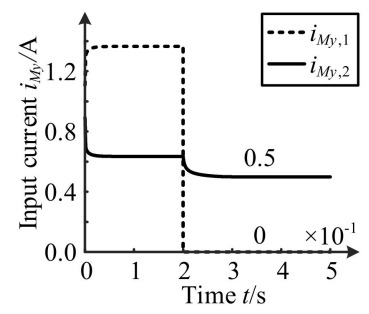

(e) Input current

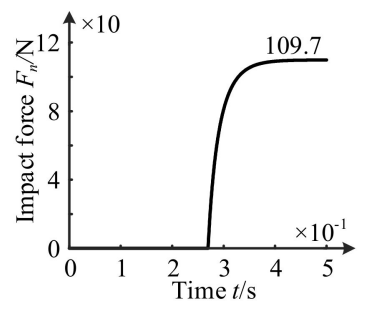

(b) Impact Force

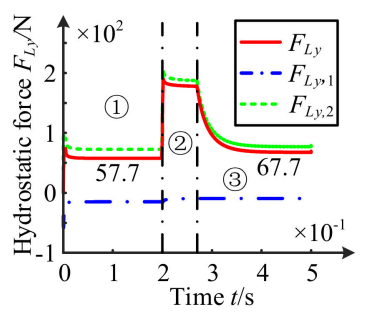

(d) Hydrostatic Force

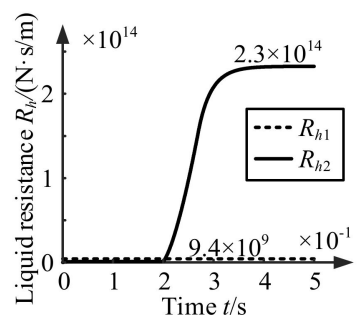

(f) Liquid resistance

Figure 5. Bearing operation rule of upper unit failure.

According to Figure 5 , the upper unit failure occurs at $t=0.2 \mathrm{~s}$, and the motion of rotor includes three stages: initial equilibrium, dropping, and collision.

In initial equilibrium stage, the rotor is dropped from zero position and stays at $-19.8 \mu \mathrm{m}$ stalely. The load is borne by electromagnetic force and hydrostatic force as shown in Stage (1).

In dropping stage, the dropping speed of rotor decreases gradually. The current $i_{M y, 1}$ of supporting unit 1 decreases to $0 \mathrm{~A}$, and the current $i_{M y, 2}$ of supporting unit 2 decreases, and then the electromagnetic force gradually approaches zero. The liquid resistance $R_{h 1}$ of supporting unit 1 remains the same basically, but the liquid resistance $R_{h 2}$ of supporting unit 2 rises rapidly due to the impact-rubbing damping effect of hydraulic oil. Therefore, the hydrostatic force increases rapidly first and then decreases slowly as shown in Stage (2).

In collision stage, the rotor reaches a new equilibrium state. As the contact depth between rotor and stator increases, the impact force $F_{n}$ increases gradually, and the external load of the rotor is balanced with electromagnetic force $F_{M y}$, hydrostatic force $F_{L y}$, and impact force $F_{n}$. The current $i_{M y, 2}$ of supporting unit 2 decreases to $0.5 \mathrm{~A}$, and the residual electromagnetic force $F_{M y}$ is $-37.4 \mathrm{~N}$. The liquid resistance $R_{h 1}$ and the liquid resistance $R_{h 2}$ are $9.4 \times 10^{9} \mathrm{~N} \cdot \mathrm{s} / \mathrm{m}$ and $2.3 \times 10^{14} \mathrm{~N} \cdot \mathrm{s} / \mathrm{m}$ respectively. However, the latter is about $2.4 \times 10^{4}$ times than the former, resulting in a tiny tremor after a collision between rotor and stator. And the hydrostatic force $F_{L y}$ gradually reduced and finally stabilized to about $67.7 \mathrm{~N}$ as shown in Stage (3).

\subsubsection{Influence Law of Operation Parameters on Rotor Impact-Rubbing Behavior}

In this failure model, the maximum radial impact force of the rotor/stator collision varies with operation parameters as shown in Figure 6. 


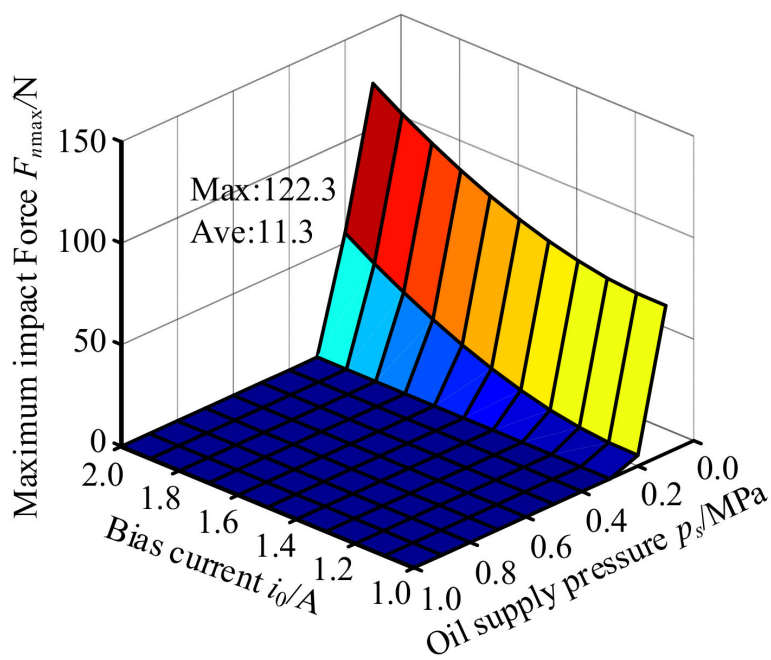

Figure 6. Maximum radial impact force under unit failure model.

According to Figure 6, collision between rotor and stator is triggered when $p_{s}<0.3 \mathrm{MPa}$. Maximum radial impact force $F_{n \max }$ decreases with the increase of the oil pocket pressure and the decrease of the bias current. The maximum value appears when $p_{s}=0.1 \mathrm{MPa}$, $i_{0}=2.0 \mathrm{~A}$. Therefore, take it as a typical example in order to analyze operation rules as shown in Figure 7.

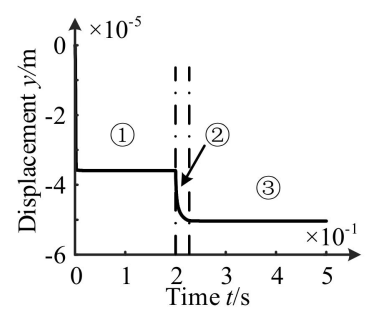

(a) Displacement

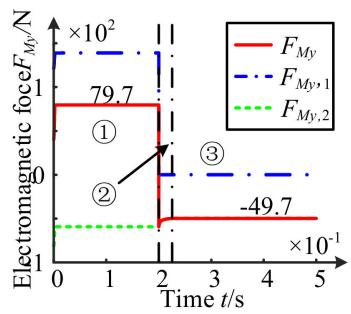

(c) Electromagnetic

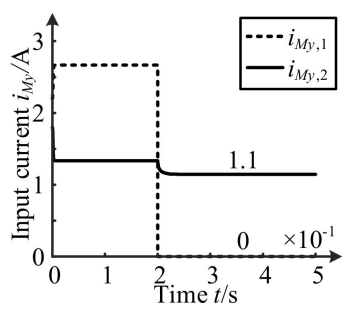

(e) Input current

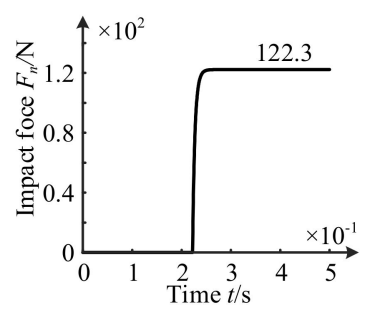

(b) Impact force

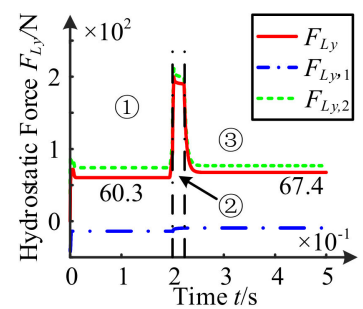

(d) Hydrostatic Force

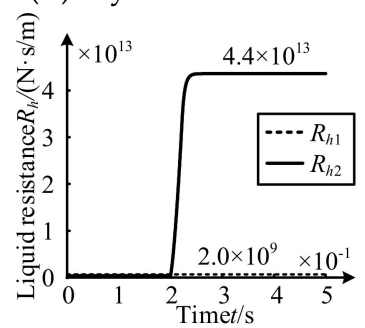

(f) Liquid resistance

Figure 7. Bearing operation rule under upper unit failure. 
According to Figure 7, in the initial equilibrium stage, the rotor drops from the zero position and stays at $-35.9 \mu \mathrm{m}$, and the external load is borne by electromagnetic force and hydrostatic force as shown in Stage (1).

In dropping stage, the dropping speed of rotor decreases gradually. The current $i_{M y, 2}$ of supporting unit 2 decreases, and the residual electromagnetic force gradually approaches zero. The liquid resistance $R_{h 2}$ of supporting pocket unit 2 increases rapidly due to the impact-rubbing damping effect of hydraulic oil. Therefore, the hydrostatic force increases rapidly first and then decreases slowly as shown in Stage (2).

In collision Stage, the rotor reaches a new equilibrium state. As the contact depth between rotor and stator gradually increases, the impact force $F_{n}$ increases, and the external load of the rotor is borne by the electromagnetic force $F_{M y}$ and hydrostatic force $F_{L y}$. The current $i_{M y, 2}$ of supporting unit 2 decreases to 1.1. In addition, the residual electromagnetic force $F_{M y}$ stabilizes to about $-49.7 \mathrm{~N}$. The liquid resistance $R_{h 1}$ and liquid resistance $R_{h 2}$ and are respectively stable at $2.0 \times 10^{9} \mathrm{~N} \cdot \mathrm{s} / \mathrm{m}$ and $4.4 \times 10^{13} \mathrm{~N} \cdot \mathrm{s} / \mathrm{m}$. The latter is about $2.2 \times 10^{4}$ times of the former, resulting in a tiny tremor after a collision between rotor and stator. The hydrostatic force $F_{L y}$ gradually decreases and stabilizes at about $67.4 \mathrm{~N}$ as shown in Stage (3).

\subsection{Drop Impact-Rubbings Behavior of Lower Unit Failure Model}

In lower unit failure model, the rotor/stator will not have collision within the range of selected structural parameters and operation parameters. A combination of $l=50 \mu \mathrm{m}$, $h_{0}=50 \mu \mathrm{m}, i_{0}=1.0 \mathrm{~A}$ and $p_{s}=0.1 \mathrm{MPa}$ was selected for analyzing as shown in Figure 8.

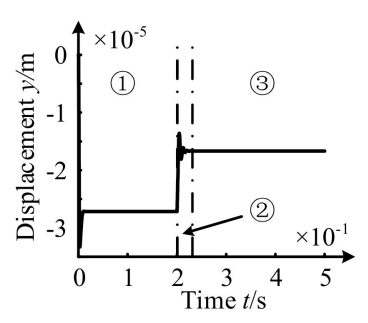

(a) Displacement

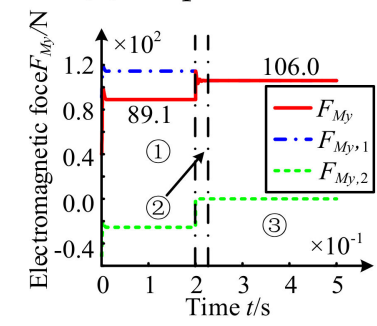

(c) Electromagnetic

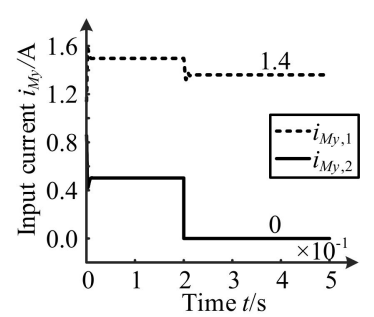

(e) Input current

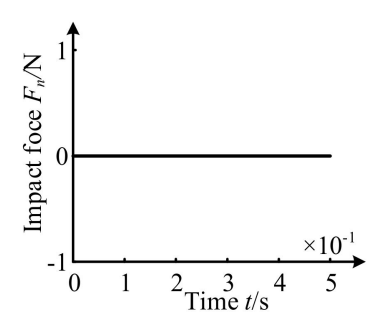

(b) Impact force

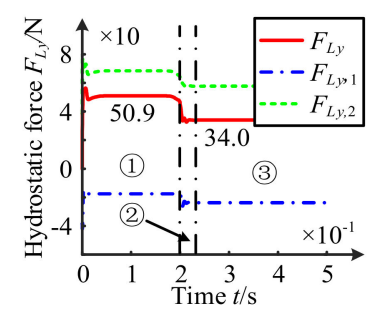

(d) Hydrostatic force

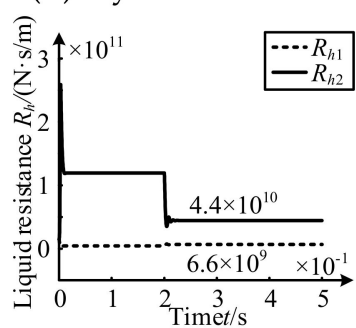

(f) Liquid resistance

Figure 8. Bearing operation rule under lower unit failure.

According to Figure 8, in the initial equilibrium stage, the rotor dropped from the zero position and stays at $-27.2 \mu \mathrm{m}$, and the load is borne by both electromagnetic force and hydrostatic force as shown in Stage (1). 
In dropping Stage, rotor dropping direction upwards and close to zero. The current $i_{M y, 1}$ of supporting unit 1 decreases, while the current $i_{M y, 2}$ of supporting unit 2 decreases to 0 . In addition, the resultant electromagnetic force increases. The liquid resistance $R_{h 1}$ has little change. While the liquid resistance $R_{h 2}$ has decreased due to the impact-rubbing damping effect of the oil. Moreover, hydrostatic force will be decrease as shown in Stage (2).

In final equilibrium Stage, rotor stabilizes at $-16.7 \mu \mathrm{m}$. The current $i_{M y, 1}$ of the supporting unit 1 decreases to $1.4 \mathrm{~A}$, leading to the electromagnetic force $F_{M y, 1}$ reducing. However, due to $F_{M y, 2}$ becomes 0 , total electromagnetic force $F_{M y}$ rises to $106.0 \mathrm{~N}$. The liquid resistance $R_{h 1}$ and $R_{h 2}$ are respectively stable at $6.6 \times 10^{9} \mathrm{~N} \cdot \mathrm{s} / \mathrm{m}$ and $4.4 \times 10^{9} \mathrm{~N} \cdot \mathrm{s} / \mathrm{m}$. In addition, hydrostatic force $F_{L y}$ drops to $34.0 \mathrm{~N}$. The rotor load is borne by both electromagnetic force and hydrostatic force as shown in Stage (3).

Compared with electromagnetic failure model of upper unit, the dropping behavior caused by this model does not cause rotor/stator collision. Therefore, it can be seen that the "fall-collision" under this model has little influence on bearing operation.

\subsection{Drop Impact-Rubbings Behavior of Bilateral Failure Models}

\subsubsection{Influence Law of Structural Parameters on Rotor Impact-Rubbing Behavior}

In bilateral failure model, the maximum radial impact force of rotor/stator collision varies with the structural parameters as shown in Figure 9.

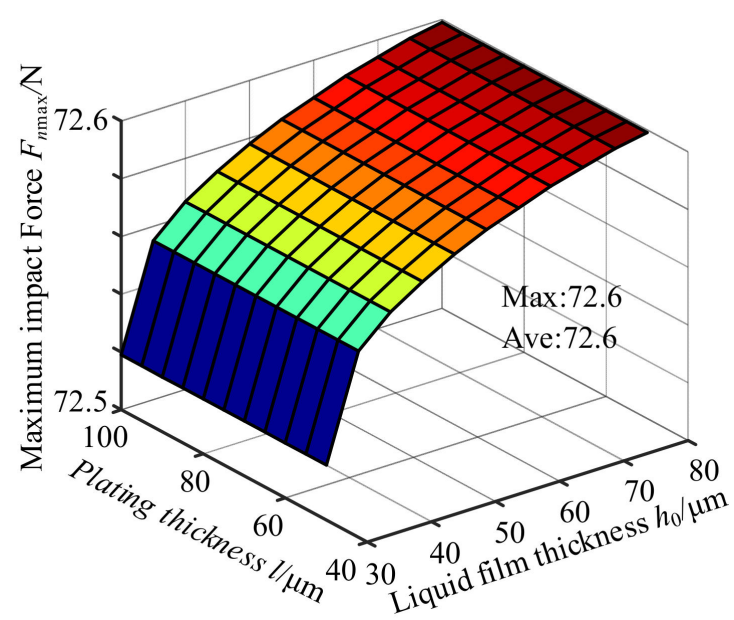

Figure 9. Maximum radial collision force bilateral failure model.

According to Figure 9, maximum impact force $F_{n \max }$ changes very little within the range of selected structural parameters, ranging from 72.5 to 72.6 . It will be invariable with the change of plating thickness, but increases with the increase of liquid film thickness. The maximum value of $F_{n \max }$ occurs in the combination of $h_{0}=80 \mu \mathrm{m}$ and $l=50 \mu \mathrm{m}$. Therefore, take it as a typical example in order to analyzing operation rules as shown in Figure 10.

According to Figure 10, in initial equilibrium stage, rotor dropped from zero position and stays at $-39.3 \mu \mathrm{m}$ after a small vibration. The load is borne by both electromagnetic force and hydrostatic force as shown in Stage (1).

In dropping Stage, rotor drops rapidly. The current $i_{M y, 1}$ of supporting unit 1 and the current $i_{M y, 2}$ decreases to 0 , and electromagnetic force also becomes 0 . The liquid resistance $R_{h 1}$ has little change, while the liquid resistance $R_{h 2}$ rises rapidly due to the impact-rubbing damping effect of oil. Therefore, the hydrostatic force increases rapidly first and then decreases slowly as shown in Stage (2).

In collision Stage, rotor reaches a new equilibrium state. As the contact depth between rotor and stator gradually increases, the impact force $F_{n}$ increases, and the load of the rotor is borne by electromagnetic force $F_{M y}$ and hydrostatic force $F_{L y}$. When electromagnetic system fails completely, and electromagnetic force $F_{M y}$ becomes 0 . The liquid resistance $R_{h 1}$ and $R_{h 2}$ are respectively stable at $5.0 \times 10^{8} \mathrm{~N} \cdot \mathrm{s} / \mathrm{m}$ and $9.0 \times 10^{12} \mathrm{~N} \cdot \mathrm{s} / \mathrm{m}$. The latter is 
about $1.8 \times 10^{4}$ times of former, resulting in a tiny tremor after a collision between rotor and stator. Moreover, hydrostatic force $F_{M y}$ decreases rapidly and finally stabilizes at about $67.4 \mathrm{~N}$ as shown in Stage (3).

Compared with upper unit failure, the variation of liquid film thickness and plating thickness does not affect the degree of rotor/stator collision. Dropping time is shorter, the stator/rotor contact arrives faster after collision Stage, the biggest impact force averages $72.6 \mathrm{~N}$, less than upper unit failure model. Thus "fall-collision" effect on the bearing system is smaller under this model.

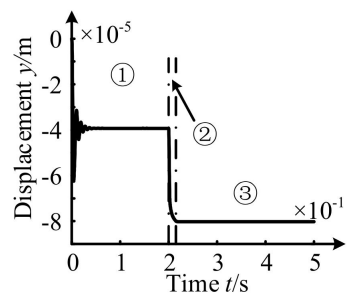

(a) Displacement

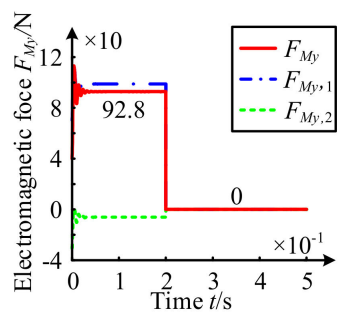

(c) Electromagnetic

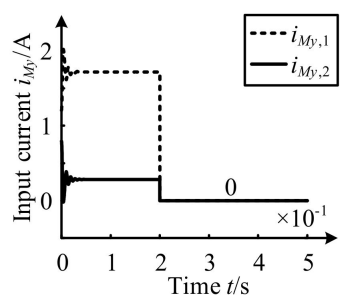

(e) Input current

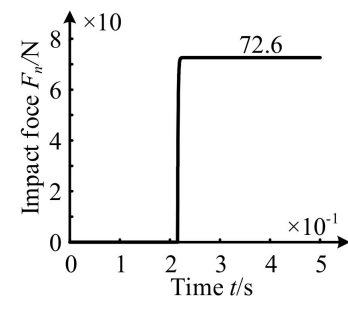

(b) Impact force

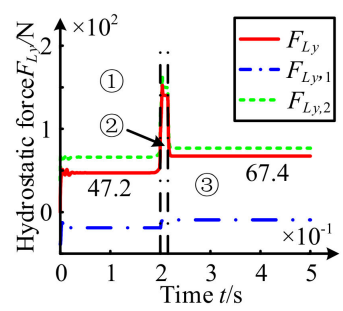

(d) Hydrostatic force

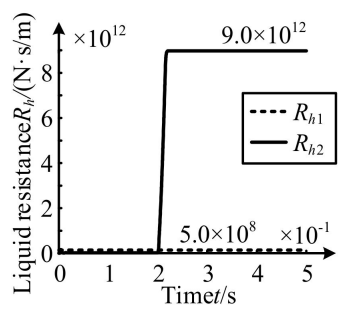

(f) Liquid resistance

Figure 10. Influence of structural parameters on bearing operation law bilateral failure.

\subsubsection{Influence Law of Operation Parameters on Rotor Impact-Rubbing Behavior}

In this model, the maximum radial impact force of rotor/stator collision changes with operation parameters as shown in Figure 11.

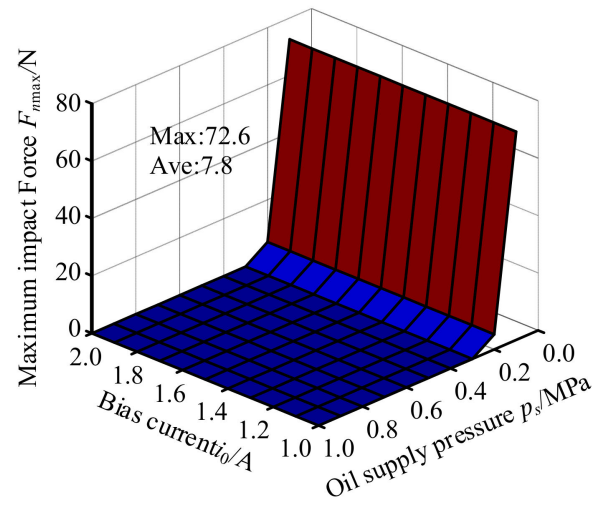

Figure 11. Maximum radial collision force bilateral failure. 
According to Figure 11, rotor/stator collision is triggered when $p_{s}<0.3 \mathrm{MPa}$. Maximum radial impact force $F_{n \text { max }}$ decreases with the increase of the oil pocket pressure and will be invariable with the change of the bias current. And its maximum value appears when $p_{s}=0.1 \mathrm{MPa}$. Therefore, take the combination of $p_{s}=0.1 \mathrm{MPa}$ and $i_{0}=2.0 \mathrm{~A}$ as a typical example in order to analyzing operation rules under this model as shown in Figure 12.

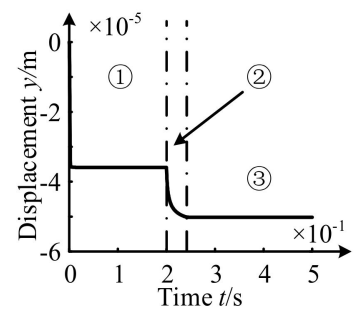

(a) Displacement

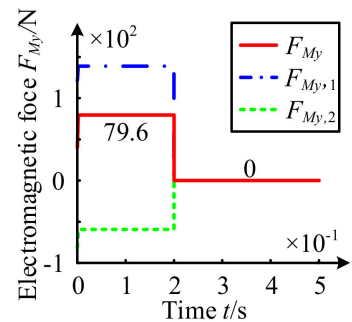

(c) Electromagnetic force

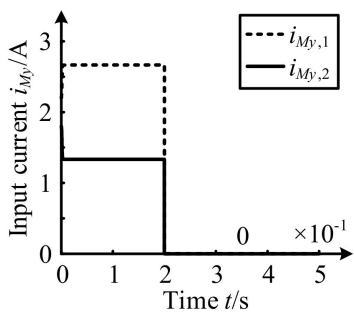

(e) Input current

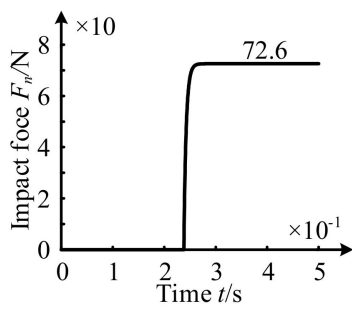

(b) Impact force

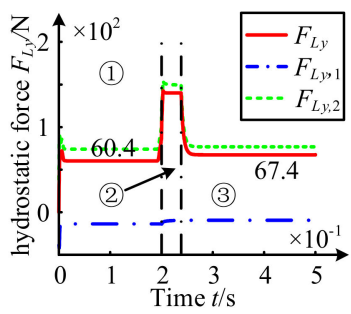

(d) Hydrostatic force

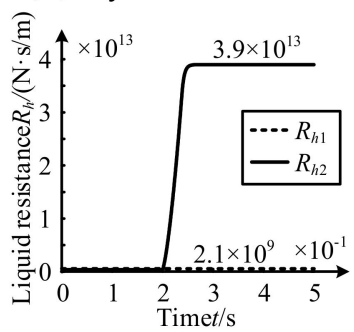

(f) Fluid resistance

Figure 12. Influence of operation Parameters on bearing operation law bilateral failure.

According to Figure 12, the rotor dropped from the zero position and stays at $-35.9 \mu \mathrm{m}$ under initial equilibrium Stage. In addition, load is borne by electromagnetic force and hydrostatic force as shown in stage (1).

In dropping Stage, the dropping speed of rotor decreases greatly. With current $i_{M y, 1}$ and current $i_{M y, 2}$ decreases to 0 , electromagnetic force also becomes 0 . The liquid resistance $R_{h 1}$ has little change, while the liquid resistance $R_{h 2}$ rises rapidly due to impact-rubbing damping effect of oil. Therefore, the hydrostatic force increases rapidly first and then decreases slowly as shown in Stage (2).

In collision Stage, rotor reaches a new equilibrium state. As contact depth between rotor and stator gradually increases, the impact force $F_{n}$ increases. In addition, the load of the rotor is borne by electromagnetic force $F_{M y}$ and hydrostatic force $F_{L y}$. The electromagnetic system fails completely, and electromagnetic force $F_{M}$ becomes 0 . The liquid resistance $R_{h 1}$ and $R_{h 2}$ are respectively stable at $2.1 \times 10^{9} \mathrm{~N} \cdot \mathrm{s} / \mathrm{m}$ and $3.9 \times 10^{13} \mathrm{~N} \cdot \mathrm{s} / \mathrm{m}$. The latter is about $1.9 \times 10^{4}$ times the former, leading to a tiny tremor after a collision between the rotor and stator. The hydrostatic force $F_{M y}$ rapidly decreases and finally stabilized to about 67.4 $\mathrm{N}$ as shown in Stage (3).

Compared with upper unit electromagnetic failure model, the variation of bias current will not affect the degree of collision. In the event of a collision area, the larger the oil chamber pressure is, the smaller the maximum radial impact force is. The mean of maximum 
radial collision force is $7.8 \mathrm{~N}$, smaller than the $11.3 \mathrm{~N}$ of upper unit electromagnetic fails. Therefore the model of "fall-collision" effect on bearing system is smaller.

\subsection{Drop Impact-Rubbings Behavior of Power Amplifier Failure Model}

\subsubsection{Influence Law of Structural Parameters on Rotor Impact-Rubbing Behavior}

In failure model of power amplifier, the maximum radial impact force of rotor/stator collision changes with the structural parameters in the case as shown in Figure 13.

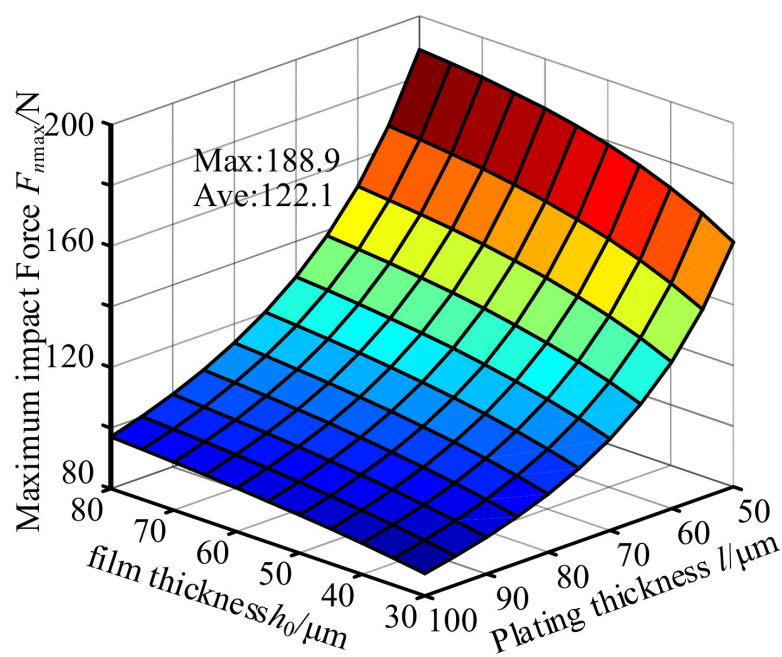

Figure 13. Maximum radial collision force.

According to Figure 13, maximum impact force $F_{n \max }$ decreases with increase of plating thickness and increases with increase of liquid film thickness. Its maximum value occurs in the combination of $h_{0}=80 \mu \mathrm{m}$ and $l=50 \mu \mathrm{m}$. Therefore, take it as a typical example in order to analyzing operation rules under this model as shown in Figure 14.

According to Figure 14, in initial equilibrium Stage, rotor is dropped from zero position and stays at $-39.3 \mu \mathrm{m}$ after a small vibration. The load is borne by electromagnetic force and hydrostatic force as shown in Stage (1).

In dropping Stage, rotor drops rapidly. The current $i_{M y, 1}$ and $i_{M y, 2}$ become $1 \mathrm{~A}$, and electromagnetic force decreases. The liquid resistance $R_{h 1}$ has little change, while the liquid resistance $R_{h 2}$ rises rapidly due to the impact-rubbing damping effect of oil. So that hydrostatic force rapidly increase as shown in Stage (2).

In collision Stage, rotor reaches a new equilibrium state. As the contact depth between rotor and stator gradually increases, the impact force $F_{n}$ increases, and the load of the rotor is borne by electromagnetic force $F_{M y}$ and hydrostatic force $F_{L y}$. The power amplifier failure, residual electromagnetic force $F_{M y}$ reduced to $116.4 \mathrm{~N}$. The liquid resistance $R_{h 1}$ and $R_{h 2}$ are stable at $5.0 \times 10^{8} \mathrm{~N} \cdot \mathrm{s} / \mathrm{m}$ and $1.1 \times 10^{13} \mathrm{~N} \cdot \mathrm{s} / \mathrm{m}$ respectively. The latter is about $2.2 \times 10^{4}$ times of the former, resulting in a tiny tremor after collision between rotor and stator. In addition, hydrostatic force $F_{M y}$ decreases rapidly and finally stabilizes to about $67.5 \mathrm{~N}$ as shown in Stage (3).

Compared with former three failure models, the liquid film thickness and plating thickness make the greater impact on the degree of collision. Moreover, the dropping time is the shortest, the rotor reaches the new equilibrium state more quickly after collision, and the mean value of maximum collision force is $122.1 \mathrm{~N}$. In addition, the phenomenon of "dropping-collision" under this model have the greatest influence on operation of the bearing. 


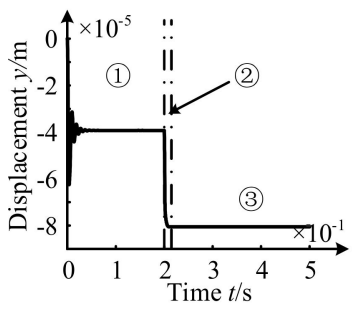

(a) Displacement

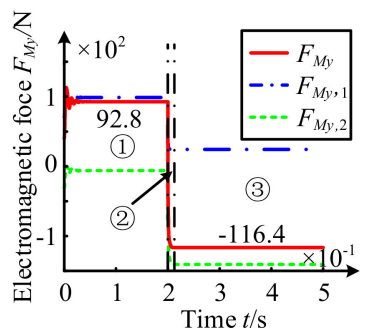

(c) Electromagnetic

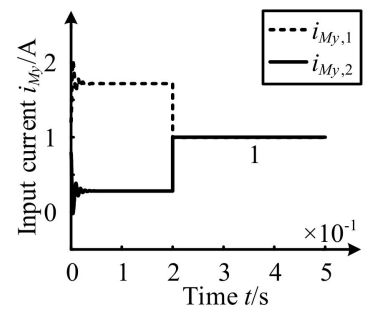

(e) Input current

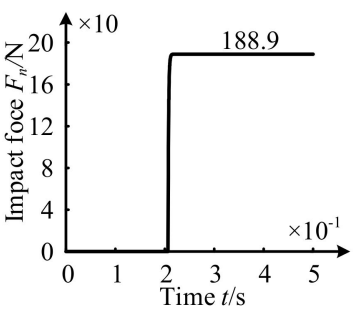

(b) Impact force

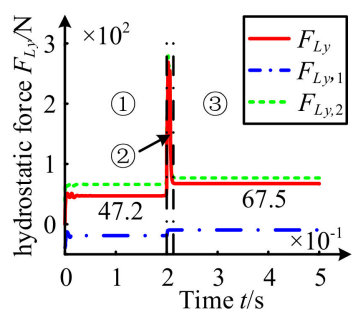

(d) Hydrostatic force

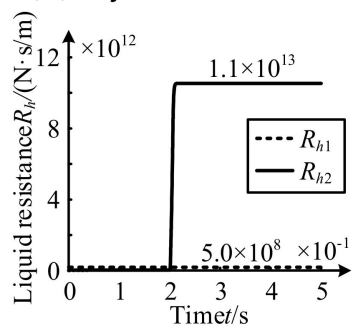

(f) Fluid resistance

Figure 14. Operation law under power amplifier failure.

3.4.2. Influence Law of Operation Parameters on Rotor Impact-Rubbing Behavior

In this model, the maximum radial impact force of rotor/stator collision changes with the operation parameters as shown in Figure 15.

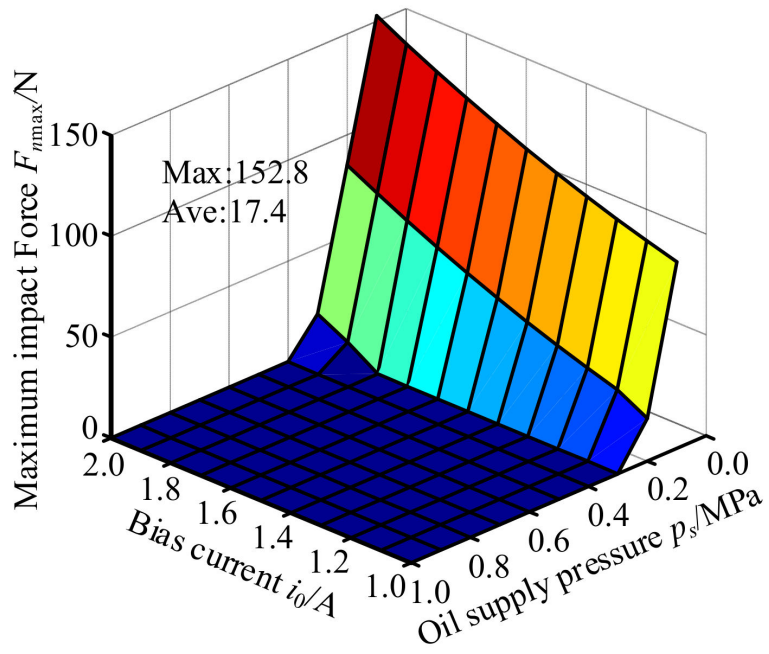

Figure 15. Maximum radial collision power under amplifier failure.

According to Figure 15, maximum radial collision force $F_{n \max }$ decreases with the increase of oil pocket pressure, and with the decreases of bias current within parameter range of collision. Its maximum value appears in the combination of $p_{s}=0.1 \mathrm{MPa}$ and 
$i_{0}=2.0 \mathrm{~A}$. Therefore, take it as a typical example in order to analyzing operation rule under this model as shown in Figure 16.

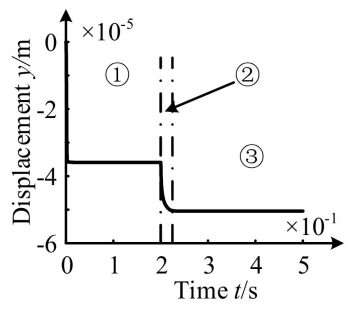

(a) Displacement

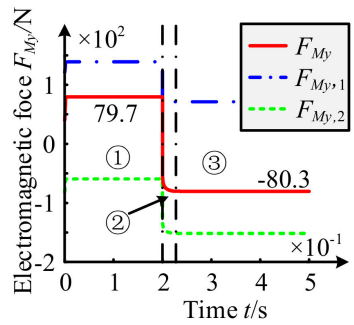

(c) Electromagnetic force

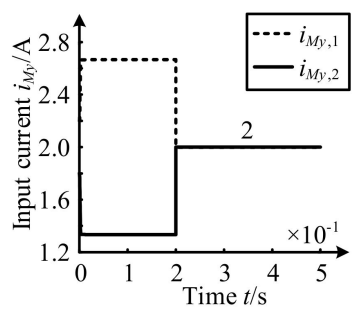

(e) Input current

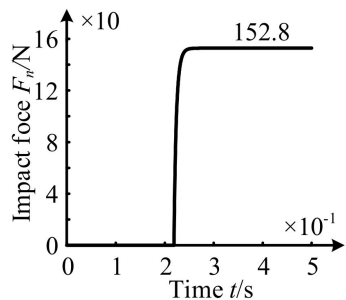

(b) Impact force

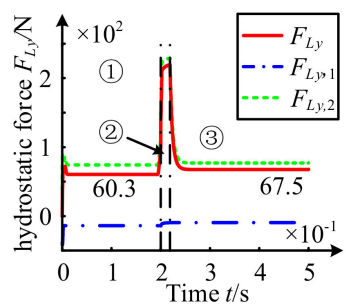

(d) Hydrostatic force

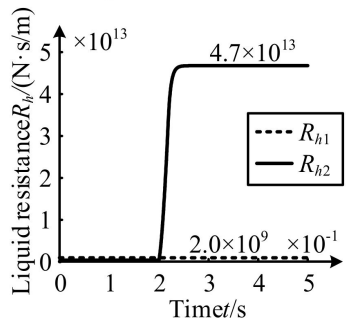

(f) Fluid resistance

Figure 16. Amplifier fails of bearing operation rule.

According to Figure 16, in initial equilibrium Stage, rotor is dropped from zero position and stays at $-35.9 \mu \mathrm{m}$. The load is borne by electromagnetic force and hydrostatic force as shown in Stage (1).

In dropping Stage, dropping speed of rotor decreases gradually. The current $i_{M y, 1}$ and $i_{M y, 2}$ change into $2 \mathrm{~A}$, and the electromagnetic force decreases. The liquid resistance $R_{h 1}$ has little change, but the liquid resistance $R_{h 2}$ rises rapidly due to the impact-rubbing damping effect of oil. So that hydrostatic force rapidly increases as shown in Stage (2).

In collision Stage, rotor reaches a new equilibrium state. As contact depth between rotor and stator gradually increases, the impact force $F_{n}$ increases. The load of the rotor is borne by the electromagnetic force $F_{M y}$ and the hydrostatic force $F_{L y}$. When the power amplifier of the electromagnetic system fails, the electromagnetic force $F_{M y}$ decreases to $-80.3 \mathrm{~N}$. The liquid resistance $R_{h 1}$ and $R_{h 2}$ are respectively stable at $2.0 \times 10^{9} \mathrm{~N} \cdot \mathrm{s} / \mathrm{m}$ and $4.7 \times 10^{13} \mathrm{~N} \cdot \mathrm{s} / \mathrm{m}$. The latter is about $2.4 \times 10^{4}$ times of the former, resulting in a tiny tremor after collision between rotor and stator. And the hydrostatic force $F_{M y}$ rapidly decreases and finally stabilizes to about $67.5 \mathrm{~N}$ as shown in Stage (3).

Compared with the former three failure models, the oil pocket pressure and bias current have a greater influence on the degree of collision. And the dropping time is the shortest. The rotor contact reaches the new equilibrium state more quickly after a collision. And the mean of maximum collision force is $17.4 \mathrm{~N}$. In addition, the phenomenon of "dropping-collision" under this model has the greatest influence on bearing operation. 
4. Experimental Study on System Impact-Rubbings in Electromagnetic Failure Model 4.1. Construction of MLDSB Test Stand

The MLDSB test stand is composed of the main body of the bearing, the electronic control system, the static pressure system, the displacement sensor, and IPC, as shown in Figure 17.

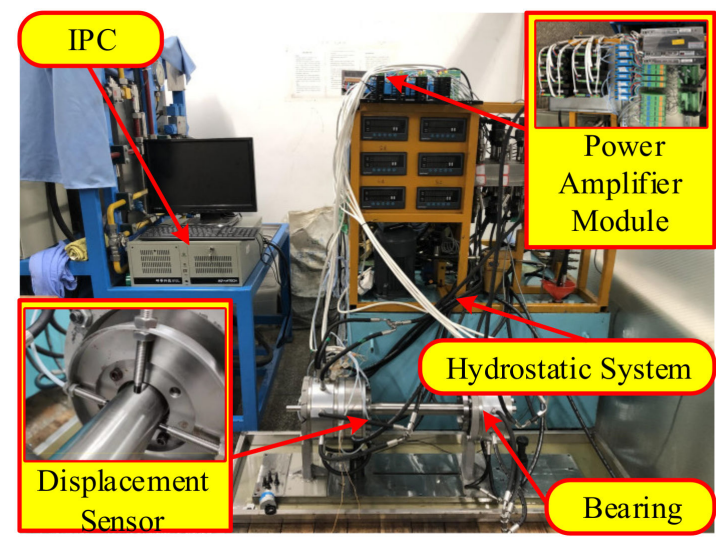

Figure 17. MLDSB test stand.

The schematic diagram of MLDSB test and interface of data acquisition and control are shown in Figures 18 and 19.

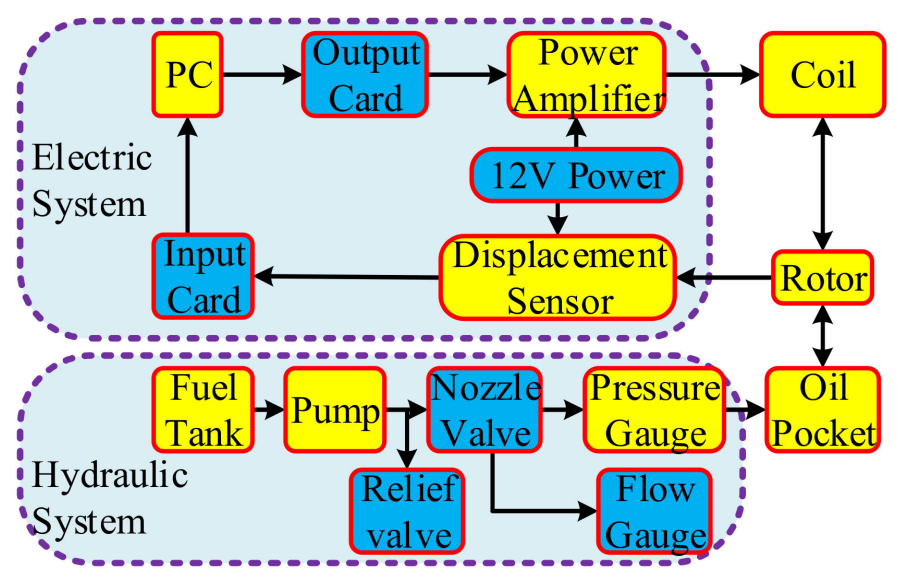

Figure 18. MLDSB schematic diagram.

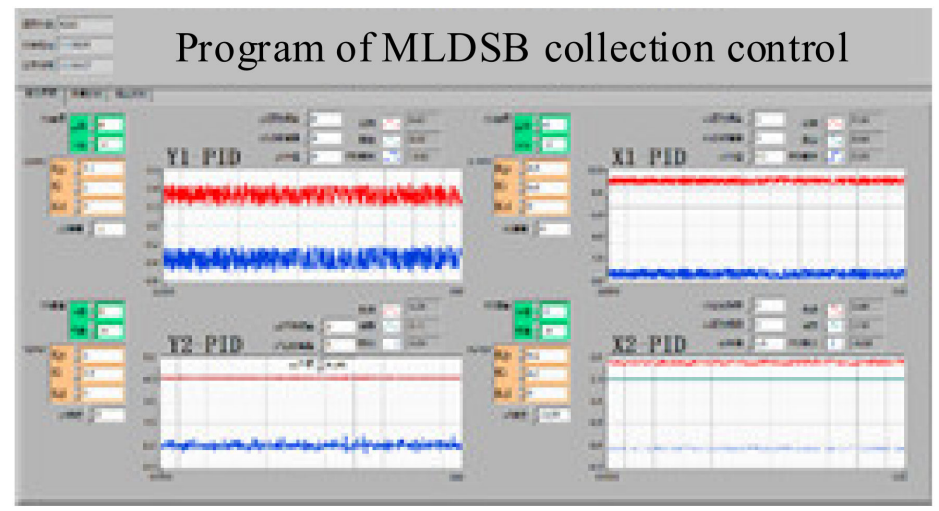

Figure 19. MLDSB data acquisition and control interface. 


\subsection{Test Procedures}

(1) Turn on the power, open on the oil pump, and operate the hydrostatic system.

(2) Adjust the output pressure of the needle valve.

(3) Operate the electromagnetic system, adjust the voltage deviation in order to suspense the rotor in the preset position;

(4) Input the PD parameter to adjust the voltage for the preset position of the rotor;

(5) Cut off the circuit of the upper unit in order to simulate the failure of the upper unit, and collect the signals of rotor displacement, oil pocket pressure, and voltage of coil.

(6) Similarly, cut off the circuit of the lower unit in order to simulate the failure of the lower unit, and collect the signals.

(7) Similarly, cut off the circuit of the upper and lower unit in order to simulate bilateral failure, and collect the signals.

(8) Set PD controller parameters to zero in order to simulate the failure of power amplifier, and collect the signals.

(9) Post treatment on stored data.

The initial parameters in the test and simulation are shown in Table 2.

Table 2. Initial test parameters of MLDSB.

\begin{tabular}{ccc}
\hline Symbol & Variable & Size \\
\hline$i_{0}$ & Biasing circuit & $0.8 \mathrm{~A}$ \\
$p_{S}$ & Supply pressure & $0.04 \mathrm{MPa}$ \\
$\mu$ & Dynamic viscosity & $0.041 \mathrm{~Pa} \cdot \mathrm{s}$ \\
$m$ & Mass of rotor & $4 \mathrm{~kg}$ \\
$\mu_{0}$ & Permeability of air & $4 \pi \times 10^{-7} \mathrm{H} / \mathrm{m}$ \\
$h_{0}$ & Oil film thickness & $70 \mu \mathrm{m}$ \\
$B$ & Flow coefficient & 0.71 \\
$S$ & Area of pole & $1080 \mathrm{~mm}^{2}$ \\
$N$ & Turns per coil & 50 \\
$Q$ & Load & $0 \mathrm{~N}$ \\
$\beta$ & Throttling ratio & 2 \\
$l$ & Plating thickness & $30 \mu \mathrm{m}$ \\
\hline
\end{tabular}

\subsection{Rotor Dynamic Behavior under Failure of Upper Unit}

The upper unit circuit is cut off, and the rotor dynamic behavior is tested as shown in Figure 20.

According to Figure 20, when the electromagnetic system of the upper unit fails, the variation trend of rotor rubbing displacement obtained by experiment is basically consistent with the theoretical simulation. The theoretical value of rotor displacement ranges from $-12.4 \mu \mathrm{m}$ to $-29.1 \mu \mathrm{m}$. The rubbing displacement is $16.7 \mu \mathrm{m}$ and the rubbing time is $0.07 \mathrm{~s}$. The experimental value ranged from $-16.6 \mu \mathrm{m}$ to $-45.2 \mu \mathrm{m}$, the rubbing displacement is $28.6 \mu \mathrm{m}$, and the rubbing time is $4.21 \mathrm{~s}$. The experimental rubbing displacement is $11.9 \mu \mathrm{m}$ larger than that the theoretical value. The rubbing time is $4.14 \mathrm{~s}$ longer than the theoretical value. This phenomenon is due to unilateral electromagnetic control adopted in the test stand and the phenomenon of oil leakage in MLDSB. It will lead to the speed of rubbing is smaller and the response time is longer.

When the upper unit fails, the pressure variation trend of the upper/lower oil obtained by experiment is basically consistent with the theoretical simulation. The theoretical value of upper pocket pressure $p_{r, 1}$ decreases from $0.060 \mathrm{MPa}$ to $0.035 \mathrm{MPa}$. The experimental value decreases from $0.070 \mathrm{MPa}$ to $0.041 \mathrm{MPa}$. The theoretical value of lower pocket pressure $p_{r, 2}$ increases from $0.161 \mathrm{MPa}$ to $0.419 \mathrm{MPa}$. The experimental value increases from $0.137 \mathrm{MPa}$ to $0.189 \mathrm{MPa}$. Because the final balance position of the rotor is lower than the initial position, the lower pocket pressure changes more than that of the upper pocket pressure. 


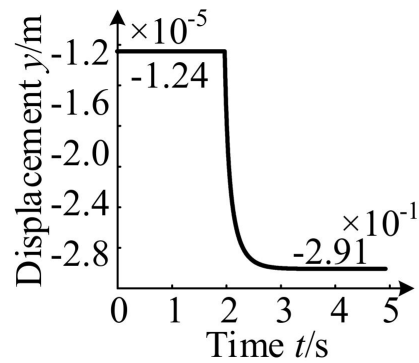

(a) Simulation displacement

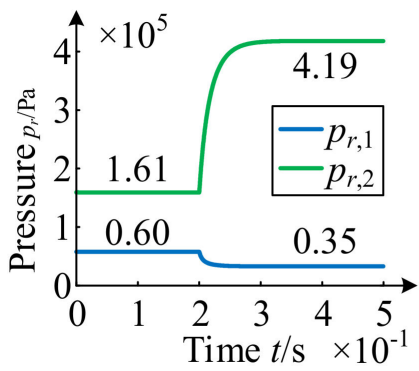

(c) Simulation oil pocket pressure

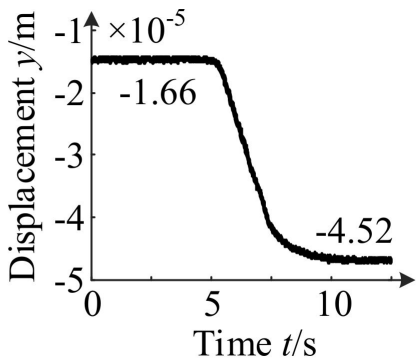

(b) Test displacement

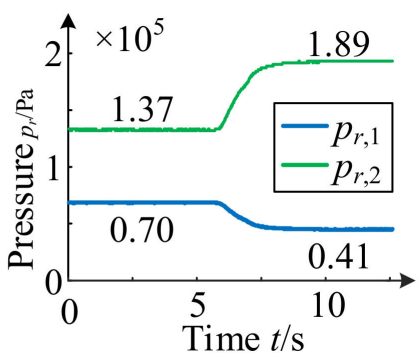

(d) Test oil pocket pressure

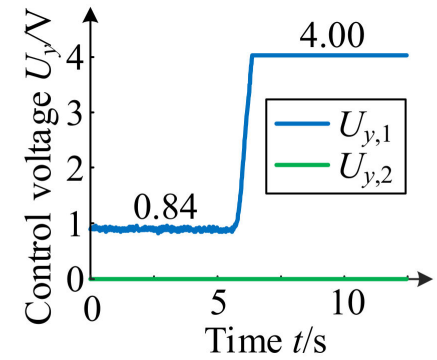

(e) Test control voltage

Figure 20. Dynamic behavior of rotor under failure of upper unit.

In order to improve the stability of the electronic control system, the unilateral control strategy is adopted to the control voltage of the electromagnetic system on the test stand. The control voltage is only input to one of the upper or lower units, and the other side is only input to the bias voltage or no voltage input. Therefore, when the displacement sensor detects the gradual decline of the rotor, the upper unit continuously increases the regulation voltage to increase the electromagnetic attraction to prevent the rotor rubbing trend. As the electromagnetic coil circuit of the upper unit is manually disconnected, the electromagnetic attraction is zero, and the rotor keeps falling until the control voltage of the upper unit reaches the limit value of $4 \mathrm{~V}$ as shown in Figure 22e. Then the rotor continues to move down until the hydrostatic system balances the rotor and reaches the new balanced state again.

\subsection{Rotor Dynamic Behavior under Failure of Lower Unit}

The lower unit circuit is cut off, and the rotor dynamic behavior is tested as shown in Figure 21. 


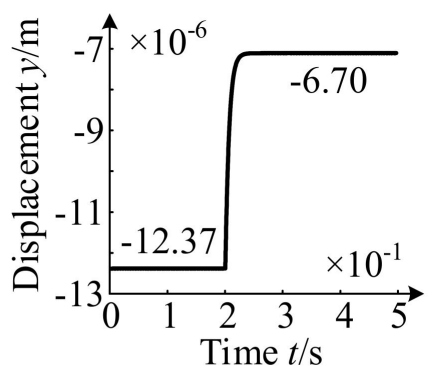

(a) Simulation displacement

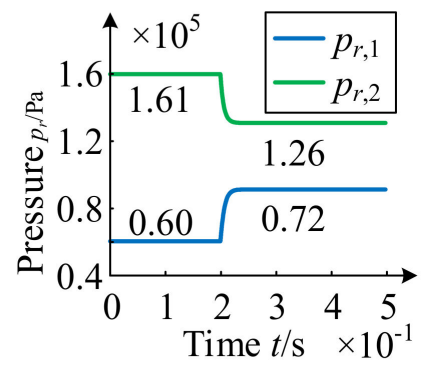

(c) Simulation oil pocket pressure

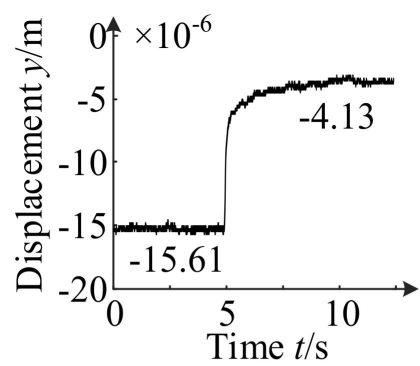

(b) Test displacement

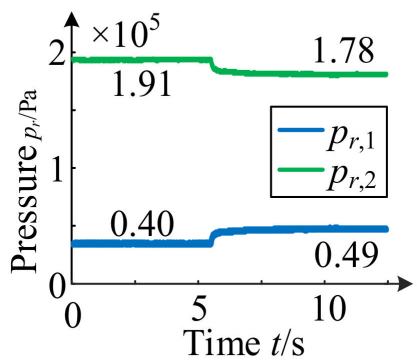

(d) Test oil pocket pressure

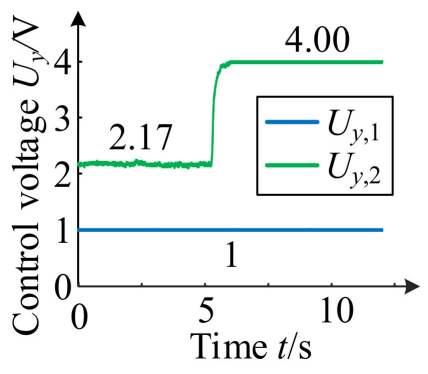

(e) Test control voltage

Figure 21. Dynamic behavior of rotor under failure of lower unit.

According to Figure 21, when the electromagnetic system of the lower unit fails, the variation trend of rotor rubbing displacement obtained by experiment is basically consistent with the theoretical simulation. The theoretical value of rotor displacement ranges from $-12.37 \mu \mathrm{m}$ to $-6.70 \mu \mathrm{m}$. The rubbing displacement is $5.67 \mu \mathrm{m}$ and the rubbing time is $0.05 \mathrm{~s}$. The experimental value ranged from $-15.61 \mu \mathrm{m}$ to $-4.13 \mu \mathrm{m}$, the rubbing displacement is $11.48 \mu \mathrm{m}$, and the rubbing time is $1.26 \mathrm{~s}$. The experimental rubbing displacement is $11.9 \mu \mathrm{m}$ larger than that the theoretical value. The rubbing time is $4.14 \mathrm{~s}$ longer than that the theoretical value. The ascending displacement obtained from the test is $5.81 \mu \mathrm{m}$ larger than the theoretical value. The ascending time is $1.21 \mathrm{~s}$ longer, accompanied by obvious tremor.

When the lower unit fails, the pressure variation trend of the upper/lower oil pocket obtained by experiment is basically consistent with the theoretical simulation. The theoretical value of upper pocket pressure $p_{r, 1}$ increases from $0.060 \mathrm{MPa}$ to $0.072 \mathrm{MPa}$. The experimental value increases from $0.040 \mathrm{MPa}$ to $0.049 \mathrm{MPa}$. The theoretical value of lower pocket pressure $p_{r, 2}$ decreases from $0.161 \mathrm{MPa}$ to $0.126 \mathrm{MPa}$. The experimental value decreases from $0.191 \mathrm{MPa}$ to $0.178 \mathrm{MPa}$.

When the lower unit fails, the rotor moves upward, and the control voltage $U_{y, 2}$ gradually increases to its limit of $4 \mathrm{~V}$, while the lower unit remains at $1 \mathrm{~V}$.

\subsection{Rotor Dynamic Behavior under Failure of Bilateral Unit}

Cut off the circuit of the upper and lower unit, and the rotor dynamic behavior is tested as shown in Figure 22. 


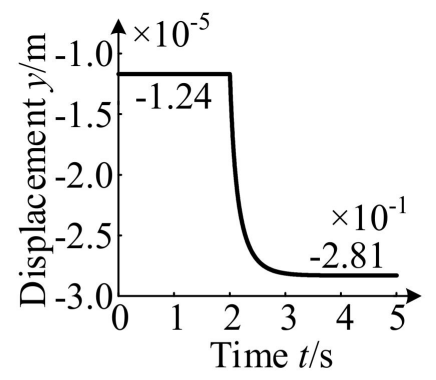

(a) Simulation displacement

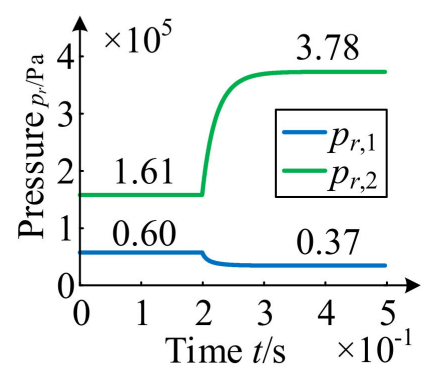

(c) Simulation oil pocket pressure

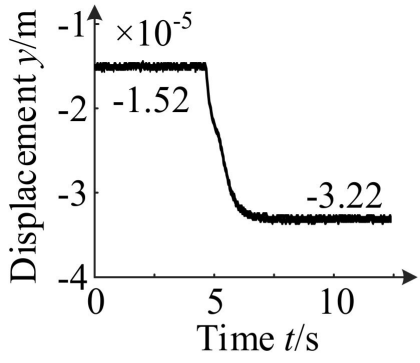

(b) Test displacement

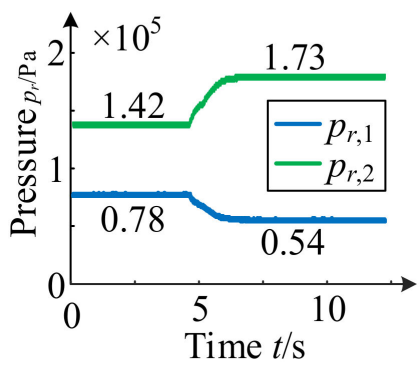

(d) Test oil pocket pressure

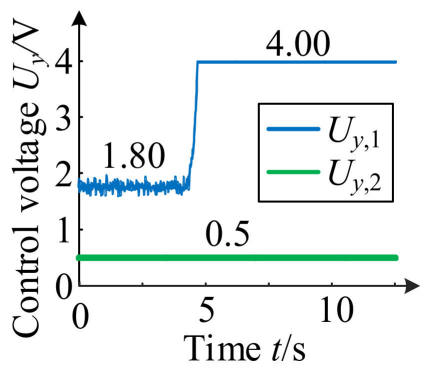

(e) Test control voltage

Figure 22. Dynamic behavior of rotor under bilateral unit failure.

According to Figure 22, when the electromagnetic system of the bilateral unit fails, the variation trend of rotor rubbing displacement obtained by experiment is basically consistent with the theoretical simulation. The theoretical value of rotor displacement ranges from $-12.4 \mu \mathrm{m}$ to $-28.1 \mu \mathrm{m}$. The rubbing displacement is $15.7 \mu \mathrm{m}$ and the rubbing time is $0.06 \mathrm{~s}$. The experimental value ranged from $-15.2 \mu \mathrm{m}$ to $-32.2 \mu \mathrm{m}$, the rubbing displacement is $17.0 \mu \mathrm{m}$, and the rubbing time is $1.48 \mathrm{~s}$. The experimental displacement is $1.8 \mu \mathrm{m}$ larger than the theoretical value. The rubbing time is $1.42 \mathrm{~s}$ longer than the theoretical value.

When the upper unit fails, the pressure variation trend of the upper/lower oil pocket obtained by experiment is basically consistent with the theoretical simulation. The theoretical value of upper pocket pressure $p_{r, 1}$ decreases from $0.060 \mathrm{MPa}$ to $0.037 \mathrm{MPa}$. The experimental value decreases from $0.078 \mathrm{MPa}$ to $0.054 \mathrm{MPa}$. The theoretical value of lower pocket pressure $p_{r, 2}$ increases from $0.161 \mathrm{MPa}$ to $0.378 \mathrm{MPa}$. The experimental value increases from $0.142 \mathrm{MPa}$ to $0.173 \mathrm{MPa}$.

The control voltage and bias voltage are respectively inputted to the upper unit and lower unit. When the upper and lower circuits are opened, the control voltage of the upper unit increases to the limit of $4 \mathrm{~V}$. While the output voltage of the lower unit remains at $0.5 \mathrm{~V}$. 


\subsection{Rotor Dynamic Behavior under Failure of Power Amplifier}

Set $K_{p}, K_{d}$ of lower unit to zero, and the rotor dynamic behavior is tested as shown in Figure 23.

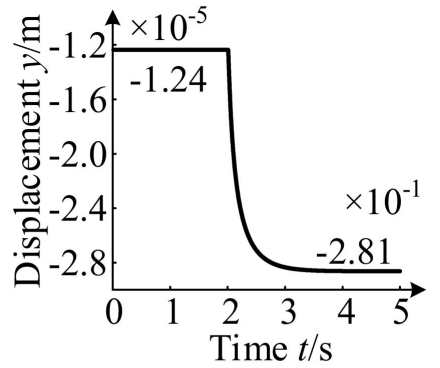

(a) Simulation displacement

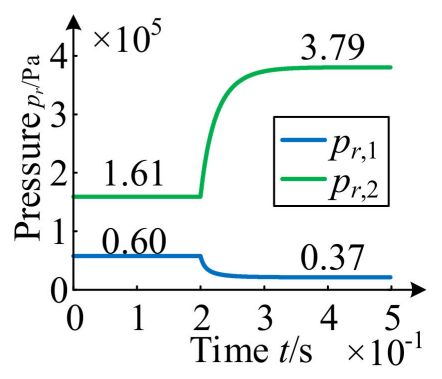

(c) Simulation oil pocket pressure

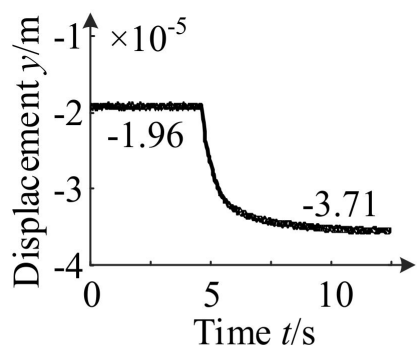

(b) Test displacement

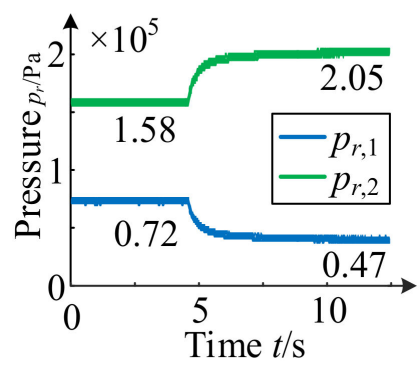

(d) Test oil pocket pressure

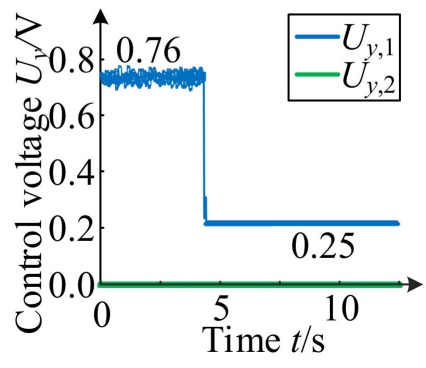

(e) Test control voltage

Figure 23. Dynamic behavior of rotor under power amplifier failure.

According to Figure 23, when the power amplifier fails, the variation trend of rotor displacement obtained by experiment is basically consistent with the theoretical simulation. The theoretical value of rotor displacement ranges from $-12.4 \mu \mathrm{m}$ to $-28.1 \mu \mathrm{m}$. The rubbing displacement is $15.7 \mu \mathrm{m}$ and the rubbing time is $0.05 \mathrm{~s}$. The experimental value ranged from $-19.6 \mu \mathrm{m}$ to $-37.1 \mu \mathrm{m}$, the rubbing displacement is $17.5 \mu \mathrm{m}$, and the rubbing time is $1.27 \mathrm{~s}$. The experimental value is $1.8 \mu \mathrm{m}$ larger than the theoretical value. The rubbing time is $1.22 \mathrm{~s}$ longer than the theoretical value.

When the power amplifier fails, the pressure variation trend of upper/lower oil pocket obtained by experiment is basically consistent with the theoretical simulation. The theoretical value of upper pocket pressure $p_{r, 1}$ decreases from $0.060 \mathrm{MPa}$ to $0.037 \mathrm{MPa}$. The experimental value decreases from $0.072 \mathrm{MPa}$ to $0.047 \mathrm{MPa}$. The theoretical value of lower pocket pressure $p_{r, 2}$ increases from $0.161 \mathrm{MPa}$ to $0.379 \mathrm{MPa}$. The experimental value increase from $0.158 \mathrm{MPa}$ to $0.205 \mathrm{MPa}$.

The control voltage is inputted to upper unit during the test. When it fails, the bias voltage is $0.25 \mathrm{~V}$. Then the rotor continues to move down until the rotor is balanced by the hydrostatic system and reaches the new balance state. 


\section{Conclusions}

(1) In the four failure modes, the "dropping-collision" phenomenon is caused by the failure of the upper unit/bilateral/power amplifier, while the failure of the lower unit does not. The "dropping-collision" degree of the bearing system caused by the four failure modes is as follows: power amplifier $>$ upper unit failure $>$ bilateral failure $>$ lower unit failure;

(2) The dynamic damping effect of hydraulic oil can inhibit and buffer the "droppingcollision" behavior of bearing system. The "dropping-collision" phenomenon can be prevented by adopting appropriate oil cavity pressure;

(3) The trend of rotor rubbing dynamic behavior obtained from the test is basically consistent with the theoretical simulation, which effectively verifies the correctness of the theoretical simulation.

Author Contributions: Conceptualization, J.Z.; Formal analysis, Y.W.; Investigation, D.G.; Methodology, G.D.; Software, L.X.; Writing—review \& editing, X.M. All authors have read and agreed to the published version of the manuscript.

Funding: This research was funded by the National Nature Science Foundation of China, grant number 52075468; General project of Natural Science Foundation of Hebei Province, grant number E2020203052; Youth Fund Project of scientific research project of Hebei University, grant number QN202013; Open Project Funding of Fluid Power Transmission Control Laboratory of Yanshan University.

Data Availability Statement: No new data were created or analyzed in this study. Data sharing is not applicable to this article.

Acknowledgments: The statements made herein are solely the responsibility of the authors.

Conflicts of Interest: The authors declare no conflict of interest.

\section{References}

1. Zhao, J.H.; Zhang, G.J.; Cao, J.B.; Gao, D.R.; Du, G.J. Decouping Control of Single DOF Supporting System of Magnetic-Liquid Double Suspension Bearing. Mach. Tool Hydraul. 2020, 48, 1-8.

2. Zhao, J.H.; Wang, Q.; Zhang, B. Influence of Liquid Film Thickness on Static Property of Magnetic-Liquid Double Suspension Bearing. In Proceedings of the International Conference on Intelligent and Interactive Systems and Applications, Beijing, China, 17-18 June 2017; pp. 809-816.

3. Xiong, W.L.; Hu, C.; Lv, L. Study on the Influence of Controlled Throttling Parameters on Hydrostatic Bearing Characteristics. J. Mech. Eng. 2017, 22, 3354-3359.

4. Zhao, J.H.; Yan, W.D.; Wang, Z.Q.; Gao, D.R. Study on Clearance-Rubbing Impact-rubbing Behavior of 2-DOF Supporting System of Magnetic-Liquid Double Suspension Bearing. Processes 2020, 8, 973. [CrossRef]

5. Zhu, L.; Wang, H. Design and Research of Test Bench for Rotor Drop Protection System. At. Energy Sci. Technol. 2015, 49, 340-386.

6. Wang, X.H.; Yang, F.F.; Zhao, Q. Analysis of Rotor Drop Impact-rubbings of Aero Engine after Electromagnetic Bearing Failure. Gas Turbine Test Study 2019, 32, 1-7.

7. Jarroux, C.; Dufour, R.; Mahfoud, J.; Defoy, B.; Alban, T.; Delgado, A. Touchdown Bearing Models for Rotor-AMB Systems. J. Sound Vib. 2018, 440, 51-69. [CrossRef]

8. Patrick, K.; Matthew, C. Dynamic conditions to destabilize persistent Rotor/touchdown bearing contact in AMB systems. Mech. Eng. J. 2017, 4, 17-00005. Available online: https://www.researchgate.net/publication/317970343_Dynamic_conditions_to_ destabilize_persistent_Rotortouchdown_bearing_contact_in_AMB_systems (accessed on 25 May 2021).

9. Pesch, A.H.; Sawicki, J.T.; Maslen, E.H. Active Magnetic Bearing Online Levitation Recovery through $\mu$-Synthesis Robust Control. Actuators 2017, 6, 2. [CrossRef]

10. Zhao, Y.L.; Gong, H.L.; Yang, G.J. Study on Control Strategy of Drop Recovery of Horizontal Rotor of Electromagnetic Bearing. Fan Technol. 2020, 62, 38-45.

11. Wei, P.; Wang, Y.F.; Yang, Y. Study on the Impact Force of High Speed Suspension Rotor Falling on Protective Bearings. Vib. Impact 2018, 37, 251-258.

12. Yu, C.T.; Xu, L.X.; Jin, C.W. Kinematics Analysis of Clearance Mechanism for Automatic Elimination of Active Magnetic Bearing System. J. Aviat. 2015, 36, 2485-2496.

13. Zhu, Y.L.; Jin, C.W. Analysis of Maximum Impact Force and Thermal Characteristics of Double Protection Bearing under High Speed and Heavy Load. China Mech. Eng. 2016, 27, 25-31. [CrossRef] 
14. Zhu, Y.L.; Jin, C.W.; Lian, C.Y. Impact-rubbing Analysis of Vertical Rotor Falling on Deep Groove Ball Bearing. Mech. Des. Res. 2016, 27, 25-31.

15. Chaowu, J.; Yili, Z.; Longxiang, X. Dynamics of Rotor Drop on New Type Catcher Bearing. Trans. Nanjing Univ. Aeronaut. Astronaut. 2014, 31, 70-77.

16. Ji, J.C.; Yu, L. Drop Dynamics of a High-Speed Unbalanced Rotor in Active Magnetic Bearing Machinery1. Mech. Struct. Mach. 2000, 28, 185-200. [CrossRef]

17. Zhu, C.S. Nonlinear Dynamics of Rotor dropping on Standby Bearings after Active Electromagnetic Bearing Failure. Lubr. Seal. 2006, 42, 196-202.

18. Jiang, L. Dynamics Study of Rotor Drop on Protective Bearing; Nanjing University of Aeronautics and Astronautics: Nanjing, China, 2011.

19. Reza, E.; Mostafa, G.; Mohammad, K.H. Nonlinear Impact-rubbing Analysis and Experimental Verification of a Magnetically Supported Flexible Rotor System with Auxiliary Bearings. Mech. Mach. Theory 2018, 121, 545-562.

20. Zhao, J.H.; Chen, T.; Wang, Q.; Zhang, B.; Gao, D.R. Stability Analysis of Single DOF Support System of Magnetic-Liquid Double Suspension Bearing. Hydro Mechatron. Eng. 2019, 47, 1-7.

21. Sudeep, V.; Anupam, D. Partially-Averaged Naiver-Stokes (PANS) Approach for Study of Fluid Flow and Heat Transfer Characteristics in Czochralski Melt. J. Cryst. Growth 2018, 481, 56-64.

22. Zhao, J.H.; Liang, Y.N.; Gao, D.R. Oil Pocket's Bearing Capacity Analysis of Liquid Hydrostatic Worktable in Gantry Moving Milling Center. Chin. J. Mech. Eng. 2014, 27, 1008-1017. [CrossRef]

23. Yang, Z.G.; Li, W.; Gou, Y.N.; Cai, T. Research on Radial Force of Permanent Magnet Synchronous Motor Based on Maxwell. J. Electr. Eng. Technol. 2020, 15, 2601-2608. [CrossRef]

24. Liu, T.; Sun, X.; Wu, J. Study on the Extraction of Collision Vibration Between Sliding Bearing and Rotor in Different Friction States. Lubr. Seal. 2018, 43, 67-71. 